\title{
Hearing Outcomes and Prognostic Factors in Idiopathic Sudden Sensorineural Hearing Loss Patients with Combined Intratympanic and Systemic Steroid Therapy
}

\author{
Min Kwan Baek ${ }^{1 *}$, Chang Hyun $\mathrm{Cho}^{1 *}$, Yu Jin Bang ${ }^{1}$, \\ Na Rae Oh ${ }^{1}$, Min Ja Baek², and Ju Hyoung Lee ${ }^{1}$ \\ ${ }^{1}$ Department of Otolaryngology-Head and Neck Surgery, Gachon University, Gil Medical Center, Incheon; and ${ }^{2}$ Department of Nursing, \\ Shingyeong University, Hwaseong, Korea
}

\begin{abstract}
돌발성 난청 환자에서 고실 내 스테로이드 및 전신 스테로이드 병용요법의 치료 성적 및 예후 인자
백민관 $^{1^{*}}$ · 조창현 ${ }^{*}$. 방유진 ${ }^{1}$ 오나래 ${ }^{1} \cdot$ 백민자 $^{2} \cdot$ 이주형 ${ }^{1}$

가천대학교 의과대학 길병원 이비인후과학교실, ${ }^{1}$ 신경대학교 간호학과 ${ }^{2}$
\end{abstract}

Received June 2,2017

Revised July 13,2017

Accepted July 24, 2017

Address for correspondence

Ju Hyoung Lee, MD, PhD

Department of Otolaryngology-

Head and Neck Surgery,

Gachon University,

Gil Medical Center,

21 Namdong-daero 774beon-gil,

Namdong-gu, Incheon 21565, Korea

Tel $+82-32-460-3763$

Fax $+82-32-467-9044$

E-mail febent@gilhospital.com

*These authors contributed equally to this work.
Background and Objectives Hearing outcomes and prognostic factors of idiopathic sudden sensorineural hearing loss (SSNHL) were investigated in patients who underwent combined intratympanic and systemic steroid therapy.

Subjects and Method This study was performed by retrospective chart review. Clinical outcomes and prognostic factors were evaluated in 147 patients who received intratympanic steroid plus systemic steroid therapy.

Results Complete hearing recovery was achieved in $36.7 \%(n=54)$ of the patients, partial recovery in $12.9 \%(n=19)$, slight recovery in $12.3 \%(n=18)$, and total recovery in $61.9 \%(n=91)$. Age was identified as an independent, negative prognostic factor for hearing recovery. The recovery rates of the down sloping and profound types were poorer than those of the up sloping type as determined by audiography.

Conclusion The results of this study suggest that the combined treatment of intratympanic and systemic steroids for idiopathic SSNHL results in high hearing recovery rates, and that the down-sloping and profound types of audiogram patterns and age are negative prognostic factors. Korean J Otorhinolaryngol-Head Neck Surg 2018;61(5):242-6

Key Words Hearing loss · Middle ear · Prognosis · Steroid · Sudden.

\section{Introduction}

Sudden sensorineural hearing loss (SSNHL) is defined as an acute loss of hearing threshold of $\geq 30 \mathrm{~dB}$ over three contiguous frequencies in less than 3 days. ${ }^{1)}$ The incidence of

This is an Open Access article distributed under the terms of the Creative Common Attribution Non-Commercial License (http://creativecommons.org/licenses/by-nc/4.0) which permits unrestricted non-commercial use, distribution, and reproduction in any medium, provided the original work is properly cited.
SSNHL has been estimated to range from 5 to 20 cases per 100000 persons per year, ${ }^{2)}$ and the etiologies of SSNHL are known to include viral infection, meningitis, syphilis, Lyme disease, acquired immunodeficiency syndrome, acoustic neuroma, and head injury. However, despite thorough searches to determine etiologies, in most cases, SSNHL is idiopathic. ${ }^{3)}$ Treatment is based on its etiology, but for idiopathic SSNHL, the most widely accepted treatment options are 
systemic steroid injection and intratympanic steroid injection. ${ }^{2)}$ Systemic steroid therapy has been proven to be effective, ${ }^{1,2)}$ but can cause unpleasant adverse effects, and cannot be administered to contraindicated subjects. Intratympanic steroid injection has been proposed as an alternative method and several studies have demonstrated its efficacy. ${ }^{4-6)}$ In addition, several studies have reported prognostic factors for idiopathic SSNHL, such as, severity of hearing loss, audiogram patterns, presence of dizziness, and age. ${ }^{1,7,8)}$

In the present study, we sought to document hearing outcomes and identify prognostic factors of idiopathic SSNHL in patients treated with intratympanic steroid plus systemic steroid.

\section{Subjects and Method}

The medical records of 147 patients diagnosed with idiopathic SSNHL from August 2011 to August 2013 were retrospectively investigated. The study protocol was approved by the Institutional Review Board of a tertiary hospital (GBIRB2013-72). Patients were excluded if they were not treated with intratympanic plus systemic steroid.

The oral steroid used was prednisolone (Solondo ${ }^{\circledR}, 5 \mathrm{mg} / \mathrm{T}$, Yuhan Corporation, Seoul, Korea), which was started at 60 $\mathrm{mg}$ and tapered gradually (days 1-5, $60 \mathrm{mg}$; days 6 and 7, 40 $\mathrm{mg}$; days 8 and 9, $20 \mathrm{mg}$; day 10, $10 \mathrm{mg}$; and day 11, $5 \mathrm{mg}$ ). Intratympanic steroid injection was performed five times at two-day intervals. Briefly, in the supine position, local anesthesia was achieved by packing with a lidocaine soaked gauze for 5 minutes. Dexamethasone $(5 \mathrm{mg} / \mathrm{mL}$, Daewon Pharmaceutical, Seoul, Korea) was then injected ( 0.3 to $0.8 \mathrm{~mL}$ ) at the anteroinferior quadrant of the tympanic membrane using a 26-gauge spinal needle and a 1-mL syringe. Patients were instructed to avoid swallowing or moving in the supine position with head tilted at $45^{\circ}$ toward the unaffected side for 20 minutes after injections.

Age, gender, pure tone audiometric thresholds before and after treatment, audiogram patterns, presence of dizziness, tinnitus, diabetes mellitus (DM), hypertension (HTN), and al- cohol and smoking history were collected from medical records. Pure tone average was produced using four frequencies $(0.5,1,2$, and $3 \mathrm{kHz})$. Eight weeks after completing treatment, final pure tone audiometric thresholds were measured. Recovery was defined as more than slight recovery, that is, patients that showed more than $15 \mathrm{~dB}$ gain and whose final hearing level was poorer than $45 \mathrm{~dB}$, as described by Siegel (Table 1). ${ }^{9)}$ Audiograms of affected ears were classified as 'up-sloping,' 'down-sloping,' 'flat,' 'U-shaped,' and 'profound.' Average thresholds were calculated at low frequency (500 and $1000 \mathrm{~Hz}$ ), mid frequency (2000 and 3000 $\mathrm{Hz}$ ), and high frequency (4000 and $6000 \mathrm{~Hz}$ ). An audiogram was characterized as up-sloping when thresholds for high frequencies were $20 \mathrm{~dB}$ less than those for low frequencies, down-sloping when low frequencies were $20 \mathrm{~dB}$ less than high frequencies, flat when the difference between high and low frequencies was within $15 \mathrm{~dB}$, U-shaped when high and low frequencies were $20 \mathrm{~dB}$ less than mid frequencies, and profound when all frequencies were $\geq 91 \mathrm{~dB}$.

Descriptive statistics are reported as proportions or means with standard deviations. Intergroup differences between initial hearing levels and ages were analyzed using the $t$ test. Categorical data were analyzed using the Fisher's exact test or Pearson's chi-square test. One-way analysis of variance was used to determine differences in age when there were four variables. When $p$ values were $<0.05$, least significant difference post hoc testing was performed to clarify group differences. Two-sided $p$ values of $<0.05$ were considered statistically significant, and the analysis was performed using SPSS version 20 (IBM Corp., Armonk, NY, USA).

\section{Results}

\section{Patient characteristics and recovery rates}

Of the 147 patients, 78 were male and 69 were female and overall average patient age was 50.1 years (range 18 to 87 years). All patients were affected unilaterally; 76 patients on the left and 71 on the right. The overall recovery rate was $61.9 \%$ $(n=91)$, that is, complete recovery $36.7 \%(n=54)$, partial recov-

Table 1. Siegel's criteria for hearing recovery ${ }^{9)}$

\begin{tabular}{ll}
\hline \multicolumn{1}{c}{ Type } & \multicolumn{1}{c}{ Hearing recovery } \\
\hline I. Complete recovery & Patients with a final hearing level improvement of $>25 \mathrm{~dB}$ regardless of the size of the gain \\
II. Partial recovery & Patients with $>15 \mathrm{~dB}$ of gain and whose final hearing level is between 25 and $45 \mathrm{~dB}$ \\
III. Slight recovery & Patients with $>15 \mathrm{~dB}$ of gain and whose final hearing level is poorer than $45 \mathrm{~dB}$ \\
IV. No improvement & Patients with a gain of $<15 \mathrm{~dB}$ \\
\hline
\end{tabular}

$\mathrm{dB}$ : decibel 
ery $12.9 \%(n=19)$, and slight recovery $12.3 \%(n=18)$.

\section{Relationship between prognostic factors and hearing recovery}

Average initial hearing levels were similar in the recovery and no recovery groups $(p=0.952)$, but older patients had significantly lower hearing recoveries $(p=0.002)$. Audiogram patterns $(p=0.047)$ and tinnitus $(p=0.013)$ were related to hearing recovery, but sex $(p=0.437)$, dizziness $(p=0.068)$, alcohol consumption $(p=0.540)$, smoking ( $p=0.985)$, hypertension ( $p=0.292$ ), and diabetes mellitus ( $p=0.563$ ) were not. The prognostic factors identified by univariate analysis were age, audiogram pattern, and tinnitus. Regarding audiogram patterns, the down-sloping type was associated with a lower recovery rate than the up-sloping type (odds ratio $=4.318, p=0.018$ ); the profound type had a lower recovery rate than the up-sloping type (odds ratio $=7.282, p=0.034$ ), and the flat and $\mathrm{U}$-shape types had marginally lower recovery rates than the up-sloping type (odds ratio $=1.961,1.574, p=0.245,0.602$ respectively) (Table 2). Multivariate analysis showed that age $(p=0.022)$ and audiogram pattern $(p=0.038)$ independently predicted hearing recovery.

\section{Relationships between prognostic factors and grade of hearing recovery}

Mean age in the complete recovery group was significantly less than in the partial recovery, slight recovery and no improve groups defined using Siegel's criteria $(p=0.026){ }^{9}{ }^{9}$ and the complete recovery group had a higher prevalence of tinnitus than the other two recovery groups $(p=0.038)$. Sex ( $p=0.334)$, audiogram pattern $(p=0.133)$, dizziness $(p=0.292)$, alcohol consumption $(p=0.170)$, smoking $(p=0.721)$, hyper-

Table 2. Relationships between hearing recovery and putative prognostic factors, as determined by univariate analysis

\begin{tabular}{|c|c|c|c|c|}
\hline Prognostic factors & Recovery, n (\%) & No recovery, n (\%) & Total, n (\%) & $p$-value \\
\hline Sex & & & & 0.437 \\
\hline Male & $46(59.0)$ & $32(41.0)$ & $78(100.0)$ & \\
\hline Female & $45(65.2)$ & $24(34.8)$ & $69(100.0)$ & \\
\hline Audiogram patterns & & & & $0.047^{*}$ \\
\hline Up sloping & $19(79.2)$ & $5(20.8)$ & $24(100.0)$ & \\
\hline Down sloping & $18(48.6)$ & $19(51.4)$ & $37(100.0)$ & \\
\hline Flat & $43(65.2)$ & $23(34.8)$ & $66(100.0)$ & \\
\hline U-shape & $8(72.7)$ & $3(27.3)$ & $11(100.0)$ & \\
\hline Profound & $3(33.3)$ & $6(66.7)$ & $9(100.0)$ & \\
\hline Dizziness & & & & 0.068 \\
\hline Presence & $12(46.2)$ & $14(53.8)$ & $26(100.0)$ & \\
\hline Absence & $79(65.3)$ & $42(34.7)$ & $121(100.0)$ & \\
\hline Tinnitus & & & & $0.013^{*}$ \\
\hline Presence & $71(68.3)$ & $33(31.7)$ & $104(100.0)$ & \\
\hline Absence & $20(46.5)$ & $23(53.5)$ & $43(100.0)$ & \\
\hline Alcohol consumption & & & & 0.540 \\
\hline Yes & $27(65.9)$ & $14(34.1)$ & $41(100.0)$ & \\
\hline No & $64(60.4)$ & $42(39.6)$ & $106(100.0)$ & \\
\hline Smoking & & & & 0.985 \\
\hline Yes & $21(61.8)$ & $13(38.2)$ & $34(100.0)$ & \\
\hline No & $70(61.9)$ & $43(38.1)$ & $113(100.0)$ & \\
\hline HTN & & & & 0.292 \\
\hline Presence & $25(55.6)$ & $20(44.4)$ & $45(100.0)$ & \\
\hline Absence & $66(64.7)$ & $36(35.3)$ & $102(100.0)$ & \\
\hline DM & & & & 0.563 \\
\hline Presence & $13(56.5)$ & $10(43.5)$ & $23(100.0)$ & \\
\hline Absence & $78(62.9)$ & $46(37.1)$ & $124(100.0)$ & \\
\hline Initial hearing level (dB) & $65.34 \pm 23.6$ & $67.2 \pm 26.4$ & & 0.952 \\
\hline Age (years) & $46.8 \pm 15.6$ & $55.6 \pm 15.6$ & & $0.002 *$ \\
\hline
\end{tabular}

$* p<0.05 . n$ : number, HTN: hypertension, DM: diabetes mellitus, dB: decibel 
Table 3. Relationships between grades of hearing recovery and putative prognostic factors: as determined by univariate analysis

\begin{tabular}{|c|c|c|c|c|c|c|}
\hline Sigel's criteria & $\begin{array}{l}\text { Complete } \\
\text { recovery, n (\%) }\end{array}$ & $\begin{array}{c}\text { Partial } \\
\text { recovery, n (\%) }\end{array}$ & $\begin{array}{c}\text { Slight recovery, } \\
n(\%)\end{array}$ & $\begin{array}{c}\text { No improve, } \\
n(\%)\end{array}$ & $\begin{array}{l}\text { Total, } \\
\text { n (\%) }\end{array}$ & $p$-value \\
\hline Sex & & & & & & 0.344 \\
\hline Male & $30(38.5)$ & $10(12.8)$ & $6(7.7)$ & $32(41.0)$ & $78(100.0)$ & \\
\hline Female & $24(34.8)$ & $9(13.0)$ & $12(17.4)$ & $24(34.8)$ & $69(100.0)$ & \\
\hline Audiogram patterns & & & & & & 0.133 \\
\hline Up sloping & $11(45.8)$ & $6(25.0)$ & $2(8.3)$ & $5(20.8)$ & $24(100.0)$ & \\
\hline Down sloping & $14(37.8)$ & $1(2.7)$ & $3(8.1)$ & $19(51.4)$ & $37(100.0)$ & \\
\hline Flat & $23(34.8)$ & $10(15.2)$ & $10(15.2)$ & $23(34.8)$ & $66(100.0)$ & \\
\hline U-shape & $5(45.5)$ & $1(9.1)$ & $2(18.2)$ & $3(27.3)$ & $11(100.0)$ & \\
\hline Profound & $1(11.1)$ & $1(11.1)$ & $1(11.1)$ & $6(66.7)$ & $9(100.0)$ & \\
\hline Dizziness & & & & & & 0.292 \\
\hline Presence & $6(23.1)$ & $3(11.5)$ & $3(11.5)$ & $14(53.8)$ & $26(100.0)$ & \\
\hline Absence & $48(39.7)$ & $16(13.2)$ & $15(12.4)$ & $42(34.7)$ & $121(100.0)$ & \\
\hline Tinnitus & & & & & & $0.038^{*}$ \\
\hline Presence & $42(40.4)$ & $17(16.3)$ & $12(11.5)$ & $33(31.7)$ & $104(100.0)$ & \\
\hline Absence & $12(27.9)$ & $2(4.7)$ & $6(14.0)$ & $23(53.5)$ & $43(100.0)$ & \\
\hline Alcoholl consumption & & & & & & 0.170 \\
\hline Yes & $20(48.8)$ & $5(12.2)$ & $2(4.9)$ & $14(34.1)$ & $41(100.0)$ & \\
\hline No & $34(32.1)$ & $14(13.2)$ & $16(15.1)$ & $42(39.6)$ & $106(100.0)$ & \\
\hline Smoking & & & & & & 0.721 \\
\hline Yes & $15(44.1)$ & $3(8.8)$ & $3(8.8)$ & $13(38.2)$ & $34(100.0)$ & \\
\hline No & 39 (34.5) & $16(14.2)$ & $15(13.3)$ & $43(38.1)$ & $113(100.0)$ & \\
\hline HTN & & & & & & 0.382 \\
\hline Presence & $12(26.7)$ & $6(13.3)$ & $7(15.6)$ & $20(44.4)$ & $45(100.0)$ & \\
\hline Absence & $42(41.2)$ & $13(12.7)$ & 11 (10.8) & $36(35.3)$ & $102(100.0)$ & \\
\hline DM & & & & & & 0.493 \\
\hline Presence & 8 (34.8) & $1(4.3)$ & $4(17.4)$ & $10(43.5)$ & $23(100.0)$ & \\
\hline Absence & $46(37.1)$ & $18(14.5)$ & $14(11.3)$ & $46(37.1)$ & $124(100.0)$ & \\
\hline Age (years) & $42.9 \pm 14.9$ & $51.3 \pm 15.7$ & $53.2 \pm 14.6$ & $55.5 \pm 15.6$ & & $0.026^{*}$ \\
\hline
\end{tabular}

$* \mathrm{p}<0.05$. $\mathrm{n}$ : number, HTN: hypertension, DM: diabetes mellitus

tension ( $p=0.382)$, and diabetes mellitus $(p=0.493)$ were not found to be related to grade of hearing recovery by univariate analysis (Table 3). Multivariate analysis showed that only age ( $p=0.039$ ) independently predicted complete recovery.

\section{Discussion}

Intratympanic steroid injections were used for the first time to treat SSNHL by Silverstein, et al. ${ }^{6)}$ in 1996. These injections are used as an initial treatment without systemic steroid, as an adjunctive treatment with systemic steroids, or as a salvage therapy after failure of systemic steroids. ${ }^{4)}$ In the most recent reports, intratympanic steroid injections have been used as a salvage therapy after failure of systemic steroids rather than as an initial treatment. ${ }^{4)}$ Several reports have shown intratympanic steroid injections have no effect when adminis- tered with systemic steroid, whereas other reports have concluded salvage therapy based on intratympanic steroid injections is effective. ${ }^{10,11)}$

Several recent studies have compared the therapeutic effects of combined systemic and intratympanic steroid therapy versus systemic steroid therapy, and shown the outcomes of combination treatment were more effective than those obtained using systemic steroids in SSNHL patients with poor prognostic factors (especially in those with poor hearing before treatment). ${ }^{12,13)}$ In our previous study, systemic steroid therapy resulted in complete recovery in $20.5 \%$, partial recovery in $16.5 \%$, slight recovery in $15.1 \%$, and non-improvement in $47.7 \%{ }^{5)}$ In the present study, intratympanic injection and systemic steroid combination therapy achieved complete recovery in $36.7 \%$, partial recovery in $12.9 \%$, slight recovery in $12.3 \%$ and non-improvement in $38.1 \%$. Thus, as compared 
to our previous study, combination therapy had higher complete recovery (36.7\% vs. $20.5 \%)$ and total recovery $(61.9 \%$ vs. $52.3 \%$ ) rates than systemic steroid therapy. ${ }^{5}$

In the present study, audiogram type was found to be related to hearing recovery. Summarizing, the down-sloping type was associated with a lower recovery rate than the up-sloping type (odds ratio $=4.318, p=0.018$ ), and the profound type with a lower recovery rate than the up-sloping type (odds ratio $=7.282, p=0.034$ ). These results are consistent with those of previous studies, in which the up-sloping and U-shape types had better prognoses than the flat, down-sloping, or profound types. ${ }^{7,8,14,15)}$ These findings suggest that high-frequency hearing loss is an important indicator of poor prognosis.

In addition, our analysis showed grade of hearing recovery, as defined by Siegel's criteria, ${ }^{9)}$ was related to age $(p=0.026)$, and tinnitus ( $p=0.038$ ), the latter of which contradicts the findings of a previous study. ${ }^{15,16)}$ Average initial hearing level was not found to be related to hearing recovery by univariate analysis ( $p=0.195)$, which is contrary to that found in previous studies. ${ }^{1,7)}$ This disparity could be due to small patient numbers, but it might also reflect the greater effectiveness of combined intratympanic and systemic steroid therapy in patients with poorer hearing before treatment. Thus, we suspect combined systemic and intratympanic steroid therapy may be more effective in patients with severe hearing loss, and suggest a study be designed to compare combined systemic and intratympanic steroid therapy and systemic therapy directly in severe hearing loss patients.

In the present study, no relation was evident between hearing recovery and hypertension or diabetes mellitus, and similarly, in previous studies, these factors were not found to be related to prognosis. ${ }^{3,715)}$ The prognostic value of dizziness remains controversial, ${ }^{15)}$ but we found no relation between it and hearing recovery. Furthermore, no relation was observed between sex, alcohol consumption, or smoking and hearing recovery, which has not been previous reported.

\section{REFERENCES}

1) Wilson WR, Byl FM, Laird N. The efficacy of steroids in the treatment of idiopathic sudden hearing loss. A double-blind clinical study. Arch Otolaryngol 1980;106(12):772-6.

2) Conlin AE, Parnes LS. Treatment of sudden sensorineural hearing loss: I. A systematic review. Arch Otolaryngol Head Neck Surg 2007; 133(6):573-81.

3) Nagaoka J, Anjos MF, Takata TT, Chaim RM, Barros F, Penido Nde O. Idiopathic sudden sensorineural hearing loss: evolution in the presence of hypertension, diabetes mellitus and dyslipidemias. Braz J Otorhinolaryngol 2010;76(3):363-9.

4) Seggas I, Koltsidopoulos P, Bibas A, Tzonou A, Sismanis A. Intratympanic steroid therapy for sudden hearing loss: a review of the literature. Otol Neurotol 2011;32(1):29-35.

5) Cho CH, Han GC, Cha HE, Woo JH. Analysis of prognostic factors in patients with sudden sensorineural hearing loss. J Clinical Otolaryngol 2005;16(4):89-95.

6) Silverstein H, Choo D, Rosenberg SI, Kuhn J, Seidman M, Stein I. Intratympanic steroid treatment of inner ear disease and tinnitus (preliminary report). Ear Nose Throat J 1996;75(8):468-71, 74, 76 passim.

7) Byl FM Jr. Sudden hearing loss: eight years' experience and suggested prognostic table. Laryngoscope 1984;94(5 Pt 1):647-61.

8) Mattox DE, Lyles CA. Idiopathic sudden sensorineural hearing loss. Am J Otol 1989;10(3):242-7.

9) Siegel LG. The treatment of idiopathic sudden sensorineural hearing loss. Otolaryngol Clin North Am 1975;8(2):467-73.

10) Rauch SD. Clinical practice. Idiopathic sudden sensorineural hearing loss. N Engl J Med 2008;359(8):833-40.

11) Rauch SD, Halpin CF, Antonelli PJ, Babu S, Carey JP, Gantz BJ, et al. Oral vs intratympanic corticosteroid therapy for idiopathic sudden sensorineural hearing loss: a randomized trial. JAMA 2011;305(20): 2071-9.

12) Arastou S, Tajedini A, Borghei P. Combined intratympanic and systemic steroid therapy for poor-prognosis sudden sensorineural hearing loss. Iran J Otorhinolaryngol 2013;25(70):23-8.

13) Gundogan O, Pinar E, Imre A, Ozturkcan S, Cokmez O, Yigiter AC. Therapeutic efficacy of the combination of intratympanic methylprednisolone and oral steroid for idiopathic sudden deafness. Otolaryngol Head Neck Surg 2013;149(5):753-8.

14) Mattox DE, Simmons FB. Natural history of sudden sensorineural hearing loss. Ann Otol Rhinol Laryngol 1977;86(4 Pt 1):463-80.

15) Xenellis J, Karapatsas I, Papadimitriou N, Nikolopoulos T, Maragoudakis $\mathrm{P}$, Tzagkaroulakis $\mathrm{M}$, et al. Idiopathic sudden sensorineural hearing loss: prognostic factors. J Laryngol Otol 2006;120(9):718-24.

16) Inoue DP, Bogaz EA, Barros F, Penido Nde O. Comparison of hearing recovery criteria in sudden sensorineural hearing loss. Braz $\mathrm{J}$ Otorhinolaryngol 2012;78(3):42-8. 